\title{
Early maladaptive schemas in individuals with and without B cluster personality disorders
}

\author{
Siamak Khodarahimi \\ Eghlid Branch, Islamic Azad University, Iran
}

The purpose of this research was to examine the role of early maladaptive schemas in patients with and without B cluster personality disorders, based on gender, age and educational status. The sample consisted of 150 Iranian outpatients with borderline, histrionic, narcissistic, and antisocial personality disorders and controls, who were selected through the purposive sampling method. A demographic questionnaire and the Young Schema Questionnaire-Short Form (YSQ-SF) were used in this study. The results demonstrated that patients with $\mathrm{B}$ cluster per- sonality disorders had significantly higher levels of early maladaptive schemas than the control group. A significant effect was found with regards to gender in relation to early maladaptive schemas. The findings did not support the influence of age or educational level in early maladaptive schemas.

\section{KEY WORDS}

early maladaptive schemas; gender; age; cluster B personality disorders

CORRESPONDING AUthor - Siamak Khodarahimi, Post Doctorate Fellowship of Psychology, Eghlid Branch, Islamic Azad University, 73815-114 Eghlid, Iran, e-mail: khodarahimi@yahoo.com

AUthors' CONTRIBUtion - A: Study design - B: Data collection - C: Statistical analysis · D: Data interpretation .

E: Manuscript preparation · F: Literature search · G: Funds collection

TO CITE THIS ARTICLE - Khodarahimi, S. (2017). Early maladaptive schemas in individuals with and without B cluster personality disorders. Current Issues in Personality Psychology, 5(4), 260-271.

RECEIVED 03.01.2017 · REVIEWED 20.02.2017 · ACCEPTED 21.03.2017 • PUBLISHED 10.06.2017 


\section{BACKGROUND}

The concept of schema was a major theoretical construct in cognitive investigations during the 1970s (Norman \& Rumelhart, 1975; Schank \& Abelson, 1977). Rumelhart (1980) defines schemas as building elements of cognition; they are units into which knowledge is structured. A schema is a cognitive structure that helps to organize an individual's perception of the world (Bem, 1983). Rumelhart (1980) proposes that schemas are like plays, which 'can be played by different actors at different times without changing the essential nature of the play' (p. 35). Schemas appear to work across multiple levels, such as universal and cultural domains (Palmer, 1996; Piaget, 1970; Strauss \& Quinn, 1997). Many studies have shown that over time, psychosis, mood and anxiety disorders are strongly influenced by a range of cognitive factors, including an individual's early schemas and maladaptive schemas (Ball, Mitchell, Malhi, Skillecorn, \& Smith, 2003; Beck, Rush, Shaw, \& Emery, 1979; Karp \& Dugas, 2003; Seavey \& Moore, 2012; Sundag, Ascone, de Matos Marques, Moritz \& Lincoln, 2016; Young \& Klosko, 2005). The role of cognitive schemas in personality disorders has been of interest to many researchers and therapists for a relatively long time (Beck et al., 1990). Young (1990) showed that maladaptive schemas result in experiencing negative events in life and these negative events are related to irregular psychological pressures. Young (1990) suggested that pathological schemas may play a major role in the development of personality disorders. Thimm (2013) observee strong relationships between early maladaptive schemas (EMSs) and maladaptive interpersonal problems using a circumplex analysis approach. Also, the concept of EMSs has great clinical importance in understanding the interaction of key factors affecting the comprehension of childhood and subconscious processes on personality disorders such as borderline and antisocial personality disorders (Arntz, 2010; Arntz, Klokman, \& Sieswerda, 2005; Arntz, \& van Genderen, 2009; Gullhaugen \& Nøttestad, 2012; Òzdel et al., 2015). For example, Òzdel and colleagues (2015) found that dependence/incompetence, defectiveness/shame, overcontrol/emotional inhibition, entitlement/grandiosity, failure to achieve, mistrust/ abuse, subjugation of needs, vulnerability to harm and illness, and social isolation, EMSs were statistically significantly higher in patients with antisocial personality disorder. In addition, research supports the schema-based role psychotherapy in patients with personality disorders (Bloo et al., 2006; Seavey \& Moore, 2012). However, there is relatively limited literature on concurrent roles of EMS in histrionic, narcissistic and antisocial personality disorders, particularly in the Middle East (Petrocelli, Glaser, Cal- houn, \& Campbell, 2001). In addition, there is a lack of evince about the roles of demographics such as gender, age and the level of education in EMSs in clinical and non-clinical samples. In this field, a few studies showed significant gender differences in EMSs. These studies indicated that women have a relatively high rate of maladaptive schemas (Balsamo, Carlucci, Sergi, Klein Murdock \& Saggino, 2015; El-Gilany, El-Bilsha, \& Ibrahim, 2013; Peixoto \& Nobre, 2015). This research is essential because EMSs are mental structures which allow people to stock up perceptual and conceptual information about their culture, and also help people to interpret cultural experiences within specific lenses in social contexts. Therefore, this study compares the EMSs in outpatients with borderline, histrionic, narcissistic and antisocial personality disorders against healthy controls, based on the roles of age, gender and educational status in an Iranian sample.

\section{THEORETICAL FRAMEWORK}

In the field of developmental psychopathology, Erikson (1963), Bowlby (1977) and Timmerman and Emmelkamp (2006) recognized the role of childhood experiences in emergence of personality disorders. In the field of cognitive schemas, Beck (1967) referred in his early writing to the role of schemas in mental disorders. This theoretical approach conceptualized that cognitive schemas have a great impact on personality disorders by production of subliminal, subconscious and automatic emotional working (Wells, 2000; Wills \& Sanders, 2013). However, there are some differences between the concept of schemas according to Beck and colleagues (1990), Young (1990) and the earlier concepts. So, the theoretical part of this study is mainly based on Young's conceptualization of EMSs.

Young (1990) speculated that schemas which form core cognitive beliefs are defined as 'organized elements of past reactions and experience that form a relatively cohesive and persistent body of knowledge capable of guiding subsequent perceptions and appraisals' (Young, 1990; p. 47). An EMS has been defined as a global and pervasive theme about oneself and one's relationships with others. An EMS develops during childhood with further developments occurring throughout an individual's lifespan. All early maladaptive schemas are relatively stable and long-term patterns, and they consist for instance of memories, physical sensations, emotions, and cognitions. It has been found that early maladaptive schemas have their origin in early childhood experiences, the innate temperament of the child, and cultural influences (Young, Klosko, \& Weishaar, 2003). The Schema-Focused Cognitive Therapy (SFCT) model is based on the assumption that most negative cognitions have their roots in childhood experiences and 
proposes an integrative systematic model of treatment for a wide spectrum of mental disorders. The four main concepts of the SFCT are: early maladaptive schemas, core emotional needs, schema modes, and maladaptive coping styles (Young, Klosko, \& Weishaar, 2003). Initially, the SFCT approach was developed for the treatment of personality disorders, particularly for the treatment of cluster B personality disorders such as borderline and narcissistic personality disorders (Ball et al., 2003; Young, Klosko, $\&$ Weishaar, 2003). According to the conceptual model of the SFCT approach, EMS is dimensional and the meaning of it depends on the levels of its severity and pervasiveness in personality disorders (Young, Klosko, \& Weishaar, 2003). Altogether, the aforesaid theories suggested that EMSs as examples of childhood, automatic and subconscious experiences have a major influence on development, continuity and maintenance of personality disorders.

\section{CLUSTER B PERSONALITY DISORDERS AND EMSS}

This study investigates the role of EMSs based on developmental psychopathology and cognitive schemas (Bowlby, 1977; Erikson, 1963; Timmerman and Emmelkamp, 2006), the CBT (Beck, 1967; Wells, 2000; Wills \& Sanders, 2013), and the SFCT (Young, 1990; Young, Klosko, \& Weishaar, 2003) conceptualizations in patients with cluster B personality disorders in comparison to individuals in the control group. Altogether, the aforesaid literature and theories shows that cluster B personality disorders have some shared elements in interpersonal, instability, dramatic, empathic, and emotional and mood regulation problems. According to DSM 5, cluster B personality disorders include borderline, histrionic, narcissistic and antisocial personality disorders (American Psychiatric Association - APA, 2013). The main objective of this study is to compare EMSs between clinical groups with the control group without B cluster personality disorders, and to explore the roles of gender, age and the level of education in these constructs among an Iranian sample. All patients with personality disorders in cluster B are presented in this study because of their difficulties in reacting to internal and external stimuli, their tendency towards novelty seeking, inability to inhibit impulsive behaviors, and dysfunctional cognitive processing and emotional dysregulation. This common figure of cluster B personality disorders overlaps with the prediction of scheme theories in personality problems. The current study suggests that maladaptive schemas are subject to the generative nature of cognitive beliefs. These schemas may establish patterns of interpersonal behavior in automatic and subconscious ways. These schematic patterns may produce maladjusted coping styles and self-defeating behavioral roles in patients with cluster B personality disorders. It is therefore possible that pervasive schemas about oneself and one's relationships with others may produce different types of personality disorders, and in turn these schemas may have implications in the treatment of patients with cluster B personality disorders. So, this study predicts that patients with cluster B personality disorders and individuals without personality disorders have different schemas because of different negative experiences in their childhood. Also, the present study proposes that age, gender and educational level variables may play a significant role in development of EMSs among patients with cluster B personality disorders. First this study hypothesized that patients with borderline, histrionic, narcissistic and antisocial personality disorders would have higher levels of early maladaptive schemas in comparison to a control group without evidence of personality disorder. The second hypothesis is that early maladaptive schemas would be influenced by age, gender and the educational level in this sample.

\section{PARTICIPANTS AND PROCEDURE}

\section{PARTICIPANTS}

Participants were 150 self-referred individuals (120 outpatients with personality disorders and 30 normal individuals without evidence of personality disorder and other health-related problems) from Shiraz, Fars province, Iran, in 2014. The clinical sample was recruited by the purposive sampling method within an ex post facto design. The purposive sampling method begins with a rationale in mind and the sample is thus chosen to involve a specific population group, and exclude those who do not suit the purpose (Palys, 2008; Tongco, 2007). The clinical sample included 30 individuals (15 males and 15 females) in each group of borderline, histrionic, narcissist and antisocial personality disorders. In 112 outpatients with personality disorders the personality disorder individual is already present in their lives as a father, mother, sibling, spouse, or a close relative. In 97 outpatients with personality disorders, the majority of interpersonal problems related to their childhood with dysfunctional parents or a personality disorder as a parent. About 22 outpatients with personality disorders have found themselves in a work relationship or marriage with someone with a personality disorder. All information about their family background was collected by the research team, but this is beyond the scope of the present study. The mean and standard deviation of age for the total sample was $M=28.76$ and $S D=3.05$. This sample included 75 males and $75 \mathrm{fe}-$ males with and without a personality disorder. The educational level of this sample ranged from high school $(N=65)$ to undergraduate $(N=85)$ levels in individuals with and without a personality disorder. 


\section{INSTRUMENTS}

The demographic questionnaire included items on age, gender, and an individual's educational level. The Young Schema Questionnaire-Short Form (YSQ$\mathrm{SF}$ ) was used for assessment of early maladaptive schemas in this study.

The Young Schema Questionnaire-Short Form (YSQ-SF; Young, 1988) is a 75-item self-report questionnaire which measures early maladaptive schemas. The YSQ-SF includes 15 subscales: Emotional Deprivation (i.e. In general, people have not been there to give me warmth, holding, and affection), Abandonment (i.e. I worry that people I feel close to will leave me or abandon me), Mistrust/Abuse (i.e. I feel that people will take advantage of me), Social Isolation (i.e. I don't belong; I'm a loner), Defectiveness (i.e. I feel that I'm not lovable), Failure (i.e. I'm not as talented as most people are at their work), Dependence (i.e. I lack common sense), Vulnerability (i.e. I worry about being attacked), Enmeshment (i.e. I often feel that I do not have a separate identity from my parent(s) or partner), Subjugation (i.e. In relationships, I let the other person have the upper hand), Self-Sacrifice (i.e. I am a good person because I think of others more than of myself), Emotional Inhibition (i.e. I find it hard to be warm and spontaneous), Unrelenting Standards (i.e. I must meet all my responsibilities), Entitlement (i.e. I hate to be constrained or kept from doing what I want), and Insufficient Self Control (i.e. I have rarely been able to stick to my resolutions). Each YSQ-SF subscale was contained by selecting the first five items with maximum loadings from every corresponding factor. Participants rate items on a Likert-type scale from 1 (Completely untrue of me), to 6 (Describes me perfectly). Items reveal a thought, feeling, or behavior linked with each schema, and is scored by summing the ratings of items in each schema. Young, Klosko and Weishaar (2003) classified all 15 schemas into 5 schema domains: (a) Disconnection and Rejection, (b) Impaired Autonomy and Performance, (c) Impaired Limits, (d) Other-Directedness, and (e) Over-vigilance and Inhibition.

Schemas in disconnection and rejection domain includes: Emotional deprivation, abandonment, mistrust/abuse, social isolation, and defectiveness. In domain I: individuals in general grew up in a family where parents did not provide sufficient love and attention, or offer supervision and direction. These individuals stay away from close relationships as they believe that their needs for nurturance and love, as well as their need to feel that they belong, will not be met (Young, Klosko, \& Weishaar, 2003). The impaired autonomy and performance domain includes: Failure, dependence, vulnerability, and enmeshment schemas. In domain II: individuals regularly have parents who weaken their self-confidence and self-esteem.
They were either overly protected by their parents or were not protected at all. As a result, it is difficult for them to set up personal goals and function autonomously (Young, Klosko, \& Weishaar, 2003). The impaired limits domain consists of subjugation and self-sacrifice schemas. In domain III: individuals usually had families that were permissive and lacked rules and boundaries (Young, Klosko, \& Weishaar, 2003). The other-directedness domain embraces emotional inhibition and unrelenting standards schemas. In domain IV: individuals have been taught that they are not allowed to follow their own ordinary inclinations (Young, Klosko, \& Weishaar, 2003). The over-vigilance and inhibition domain contains entitlement and insufficient self-control schemas. In domain V: individuals most likely had harsh parents who treasured self-control and self-denial. These individuals are highly susceptible to perceiving life events as negative and they view life as bleak (Young, Klosko, \& Weishaar, 2003).

The validity and reliability of the YSQ-SF was affirmed in both clinical and no-clinical studies (Schmidt, Joiner, Young, \& Telch, 1995; Trip, 2006; Welburn, Coristine, Dagg, Pontefract, \& Jordan 2002; Young, 1988). Research with the Persian language version of the YSQ-SF confirmed its validity and reliability in Iran (Sadooghi, Aguilar-Vafaie, Rasoulzadeh Tabatabaie, \& Esfehanian, 2008). Reliability of the YSQ-SF, disconnection and rejection, impaired autonomy and performance, impaired limits, other-directedness, and over-vigilance and inhibition domains was established using Cronbach's $\alpha$ internal consistency in the present study and was found to be $.94, .89, .88, .86, .92$ and .90 respectively.

\section{PROCEDURE}

The sample was chosen based on a purposive sampling method (Palys, 2008; Tongco, 2007). Then, individuals in the control group were matched with demographic variables of participants in the clinical group. Individuals in the clinical group were assigned from the private clinic. Patients with personality disorders were included in this project if they met the following criteria: (a) the patient presented with the full clinical features of borderline, histrionic, narcissistic and antisocial personality disorders based on the DSM-IV-TR and verified by two clinical psychologists, (b) the patient was under treatment for borderline, histrionic, narcissistic and antisocial personality disorders with a clinical psychologist, (c) the patient did not have a comorbid mental disorder or physiological disease based on the DSM-V and the clinical assessment of a neurologist, and (d) the patient volunteered to participate in this study. All individuals in the control group were evaluated for personality disorders, other mental disorders and 
physiological diseases by clinicians from different specialties including clinical psychology, psychiatry, neurology, and general medicine. After informed consent was acquired, participants completed a demographic sheet and one measure. In this study the demographic questionnaire and the measure were completed in person by participants in both clinical and control groups. Participants in the clinical group received free psychotherapeutic services as their compensation for their contribution to this study. Participants in the control group received a token compensation for the time they spent in this study.

This is an independent research, but it's ethical standards approved by Rasti Psychotherapy Clinic; Shiraz, Iran.

\section{DATA ANALYSIS}

The SPSS 18 software was used for data analysis in this study (Bryman \& Duncan, 2011). The main statistical methods for testing of hypotheses were the multivariate analysis of covariance (MANCOVA), one-way analysis of variance (ANOVA), and Duncan test post-hoc. The significance level for hypothesis testing was $\alpha=.05$.

\section{RESULTS}

To evaluate these two hypotheses in this study a multivariate analysis of covariance (MANCOVA) by group status, gender, age and educational level (as fixed independent variables) and maladaptive schemas (i.e. 15 schemas and 5 schematic domains) as dependent variables were computed in this sample. This analysis included 20 dependent and 4 independent variables. This analysis showed the role of group status (Wilks' $k=.007 ; F(60,392)=16.68 ; p<.001)$ in all dependents variables. Tests of between-subjects effects showed that patients with personality disorders have greater scores in all 15 maladaptive schemas than individuals in the control group. Also, tests of between-subjects effects indicated that patients with personality disorders have superior scores in five domains of early maladaptive schemas than individuals in the control group (Table 1).

To carefully examine the first hypothesis in this study, 20 one-way analyses of variances (ANOVAs) for dependent variables were performed to evaluate the differences between patients with borderline, histrionic, narcissistic and antisocial personality disorders, and individuals in the control group. The between-subjects effects test showed the significant role of group status in emotional deprivation, $F(4,149)=90.93, p<.001 ;$ abandonment, $F(4,149)$ $=109.83, p<.001$; mistrust $/$ abuse, $F(4,149)=66.32$, $p<.001$; social isolation, $F(4,149)=128.70, p<.001$; defectiveness, $F(4,149)=116.11, p<.001$; failure, $F(4,149)=74.21, p<.001 ;$ dependence, $F(4,149)=$ $173.55, p<.001$; vulnerability, $F(4,149)=138.88$, $p<.001$; enmeshment, $F(4,149)=85.85, p<.001$; subjugation, $F(4,149)=122.29, p<.001$; self-sacrifice, $F(4,149)=173.11, p<.001$; emotional inhibition, $F(4,149)=136.24, p<.001$; unrelenting standards, $F(4,149)=79.47, p<.001$; entitlement, $F(4,149)=153.34, p<.001$; insufficient self-control, $F(4,149)=144.94, p<.001$; disconnection and rejection, $F(4,149)=228.84, p<.001$; impaired autonomy and performance, $F(4,149)=375.41, p<.001$; impaired limits, $F(4,149)=240, p<.001$; other-directedness, $F(4,149)=250.49, p<.001$; and overvigilance and inhibition, $F(4,149)=280.59, p<.001$. The post-hoc comparisons performed using the Duncan test showed significant group differences for all maladaptive schemas and its five domains in this sample (Table 1).

In the second hypothesis, the MANOVA analysis affirmed the significant role of gender (Wilks' $k=.726$; $F(15,100)=2.51 ; p<.003)$ in dependent variables. Tests of between-subjects effects showed significant gender differences in mistrust/abuse, emotional inhibition, impaired autonomy and performance, and self-sacrifice in this sample (Table 2).

Similarly, the MANOVA confirmed the effect of group status and gender interaction (Wilks' $k=.273$; $F(60,392)=2.12 ; p<.001)$ in dependent variables. The between-subjects effects test showed the significant role of group status and gender interaction in emotional deprivation, mistrust/abuse, vulnerability, enmeshment, subjugation, unrelenting standards, and insufficient self-control schemas. Also, the between-subjects effects test revealed the significant role of group status and gender interaction in disconnection and rejection, other-directedness, and over-vigilance and inhibition domains of early maladaptive schemas (Table 3).

Finally, the MANOVA rejected the influences of age (Wilks' $k=.829 ; F(15,100)=1.38 ; p<.170)$ and educational level (Wilks' $k=.927 ; F(15,100)=.524$; $p<.920)$ in all dependent variables.

\section{DISCUSSION}

The results for the first hypothesis showed significant group differences for all EMSs. The Duncan post-hoc test showed that patients with cluster B personality disorders had significantly higher scores in emotional deprivation, abandonment, mistrust/abuse, social isolation, defectiveness, failure, dependence, vulnerability, enmeshment, subjugation, self-sacrifice, emotional inhibition, unrelenting standards, entitlement and insufficient self-control than individuals in the control group.

Post-hoc comparisons showed that patients with borderline, histrionic and narcissistic personality 
Table 1

Tests of between-subjects effects of maladaptive schemas in clinical and control groups

\begin{tabular}{|c|c|c|c|c|c|c|c|c|c|c|c|c|}
\hline \multirow[t]{3}{*}{ Dependents } & \multicolumn{10}{|c|}{ Groups } & \multirow[t]{3}{*}{$F$} & \multirow[t]{3}{*}{$p$} \\
\hline & \multicolumn{2}{|c|}{ BPD } & \multicolumn{2}{|c|}{ HPD } & \multicolumn{2}{|c|}{ NPD } & \multicolumn{2}{|c|}{ APD } & \multicolumn{2}{|c|}{ Control } & & \\
\hline & $M$ & $S D$ & $M$ & $S D$ & $M$ & $S D$ & $M$ & $S D$ & $M$ & $S D$ & & \\
\hline $\begin{array}{l}\text { Emotional } \\
\text { deprivation }\end{array}$ & 22.00 & 0.88 & 22.06 & 0.82 & 22.88 & 0.83 & 23.08 & 0.82 & 6.82 & 0.85 & 62.92 & .001 \\
\hline Abandonment & 20.87 & 0.76 & 21.62 & 0.70 & 22.85 & 0.72 & 23.79 & 0.70 & 7.87 & 0.73 & 80.80 & .001 \\
\hline Mistrust/Abuse & 18.78 & 0.85 & 21.13 & 0.79 & 22.20 & 0.80 & 23.70 & 0.79 & 9.84 & 0.82 & 41.23 & .001 \\
\hline Social isolation & 20.86 & 0.66 & 21.20 & 0.61 & 23.26 & 0.63 & 22.67 & 0.61 & 7.87 & 0.64 & 96.47 & .001 \\
\hline Defectiveness & 19.89 & 0.69 & 21.82 & 0.64 & 23.17 & 0.65 & 23.81 & 0.64 & 7.44 & 0.66 & 102.77 & .001 \\
\hline Failure & 18.46 & 0.95 & 19.44 & 0.88 & 21.61 & 0.89 & 22.01 & 0.88 & 6.34 & 0.92 & 48.74 & .001 \\
\hline Dependence & 21.62 & 0.64 & 22.28 & 0.59 & 21.73 & 0.61 & 25.98 & 0.59 & 6.81 & 0.62 & 146.28 & .001 \\
\hline Vulnerability & 21.65 & 0.66 & 20.24 & 0.61 & 20.60 & 0.63 & 23.07 & 0.61 & 7.09 & 0.64 & 100.16 & .001 \\
\hline Enmeshment & 19.68 & 0.81 & 19.25 & 0.76 & 20.94 & 0.77 & 23.16 & 0.76 & 7.98 & 0.79 & 52.27 & .001 \\
\hline Subjugation & 18.07 & 0.64 & 16.75 & 0.59 & 21.47 & 0.61 & 22.02 & 0.59 & 7.74 & 0.62 & 82.68 & .001 \\
\hline Self-sacrifice & 16.62 & 0.62 & 21.87 & 0.57 & 22.53 & 0.59 & 21.56 & 0.57 & 7.30 & 0.60 & 100.87 & .001 \\
\hline $\begin{array}{l}\text { Emotional } \\
\text { inhibition }\end{array}$ & 20.54 & 0.66 & 21.07 & 0.61 & 21.73 & 0.62 & 23.47 & 0.61 & 6.14 & 0.64 & 116.82 & .001 \\
\hline $\begin{array}{l}\text { Unrelenting } \\
\text { standards }\end{array}$ & 18.47 & 0.72 & 20.95 & 0.67 & 20.93 & 0.69 & 21.39 & 0.67 & 7.22 & 0.70 & 64.51 & .001 \\
\hline Entitlement & 21.33 & 0.71 & 18.00 & 0.66 & 22.31 & 0.67 & 24.47 & 0.66 & 6.22 & 0.68 & 105.25 & .001 \\
\hline $\begin{array}{l}\text { Insufficient self } \\
\text { control }\end{array}$ & 19.66 & 0.58 & 19.15 & 0.53 & 22.46 & 0.54 & 23.58 & 0.53 & 6.92 & 0.56 & 130.98 & .001 \\
\hline $\begin{array}{l}\text { Disconnection } \\
\text { and rejection }\end{array}$ & 102.44 & 2.41 & 107.92 & 2.24 & 116.42 & 2.28 & 117.12 & 2.23 & 39.85 & 2.33 & 183.55 & .001 \\
\hline $\begin{array}{l}\text { Impaired } \\
\text { autonomy and } \\
\text { performance }\end{array}$ & 81.42 & 1.65 & 81.22 & 1.54 & 84.90 & 1.56 & 94.23 & 1.53 & 28.23 & 1.604 & 263.29 & .001 \\
\hline Impaired limits & 34.69 & 0.93 & 38.62 & 0.87 & 44.00 & 0.88 & 43.58 & 0.86 & 15.04 & 0.906 & 161.46 & .001 \\
\hline $\begin{array}{l}\text { Other- } \\
\text { directedness }\end{array}$ & 39.02 & 0.88 & 42.02 & 0.82 & 42.66 & 0.83 & 44.87 & 0.82 & 13.36 & 0.857 & 214.58 & .001 \\
\hline $\begin{array}{l}\text { Overvigilance } \\
\text { and inhibition }\end{array}$ & 41.00 & 0.94 & 37.15 & 0.87 & 44.77 & 0.89 & 48.05 & 0.87 & 13.14 & 0.914 & 216.80 & .001 \\
\hline
\end{tabular}

Note. BPD - Borderline Personality Disorder, HPD - Histrionic Personality Disorder, NPD - Narcissistic Personality Disorder, APD - Antisocial Personality Disorder.

disorders had significantly lower scores in emotional deprivation than patients with antisocial personality disorders. The Duncan post-hoc test showed that patients with borderline and histrionic personality disorders had significantly lower scores in abandonment, mistrust/abuse, social isolation, defectiveness, failure, dependence, enmeshment, subjugation, and self-sacrifice than patients with narcissistic and antisocial personality disorders, while patients with borderline, histrionic, narcissistic and antisocial personality disorders did not have any significant dif- ferences in vulnerability and emotional inhibition schemas.

Post-hoc comparisons demonstrated that patients with borderline personality disorder had significantly lower scores in self-sacrifice, unrelenting standards, entitlement and insufficient self-control than patients with histrionic, narcissistic and antisocial personality disorders. In disconnection and rejection, impaired autonomy and performance, impaired limits, other-directedness and over-vigilance and inhibition, patients with borderline, histrionic, narcissistic and 
Table 2

Tests of between-subjects effect for gender differences in maladaptive schemas

\begin{tabular}{|c|c|c|c|c|c|c|}
\hline \multirow[t]{3}{*}{ Dependents } & \multicolumn{4}{|c|}{ Groups } & \multirow[t]{3}{*}{$F$} & \multirow[t]{3}{*}{$p$} \\
\hline & \multicolumn{2}{|c|}{ Males } & \multicolumn{2}{|c|}{ Females } & & \\
\hline & M & $S D$ & $M$ & $S D$ & & \\
\hline $\begin{array}{l}\text { Emotional } \\
\text { deprivation }\end{array}$ & 19.58 & 6.19 & 18.92 & 7.85 & 2.50 & .110 \\
\hline Abandonment & 17.88 & 6.24 & 19.65 & 6.78 & 2.96 & .080 \\
\hline Mistrust/Abuse & 18.14 & 5.88 & 19.58 & 6.28 & 4.56 & .030 \\
\hline Social isolation & 18.01 & 5.75 & 19.50 & 6.70 & 3.40 & .060 \\
\hline Defectiveness & 18.18 & 6.01 & 19.30 & 7.21 & 0.42 & .510 \\
\hline Failure & 16.74 & 6.81 & 17.90 & 6.97 & 2.81 & .090 \\
\hline Dependence & 19.44 & 6.89 & 19.29 & 7.19 & 0.40 & .520 \\
\hline Vulnerability & 18.52 & 7.17 & 18.73 & 6.24 & 0.90 & .340 \\
\hline Enmeshment & 17.98 & 6.68 & 18.98 & 6.78 & 3.06 & .080 \\
\hline Subjugation & 17.38 & 6.18 & 17.01 & 6.04 & 0.73 & .390 \\
\hline Self-sacrifice & 19.22 & 6.13 & 16.94 & 6.39 & 8.00 & .006 \\
\hline Emotional inhibition & 18.20 & 6.91 & 19.25 & 7.24 & 11.08 & .001 \\
\hline $\begin{array}{l}\text { Unrelenting } \\
\text { standards }\end{array}$ & 17.64 & 5.89 & 17.93 & 6.65 & 0.78 & .370 \\
\hline Entitlement & 18.20 & 6.64 & 18.28 & 7.22 & 0.06 & .800 \\
\hline $\begin{array}{l}\text { Insufficient self } \\
\text { control }\end{array}$ & 19.17 & 6.88 & 17.28 & 6.89 & 1.72 & .190 \\
\hline $\begin{array}{l}\text { Disconnection } \\
\text { and rejection }\end{array}$ & 91.81 & 26.75 & 96.97 & 32.83 & 2.00 & .160 \\
\hline $\begin{array}{l}\text { Impaired autonomy } \\
\text { and performance }\end{array}$ & 72.69 & 24.63 & 74.92 & 24.83 & 6.04 & .010 \\
\hline Impaired limits & 36.61 & 11.56 & 33.96 & 11.56 & 1.67 & .190 \\
\hline Other-directedness & 35.84 & 11.60 & 37.18 & 12.75 & 3.08 & .080 \\
\hline $\begin{array}{l}\text { Overvigilance } \\
\text { and Inhibition }\end{array}$ & 37.37 & 12.94 & 35.56 & 13.39 & 0.38 & .530 \\
\hline
\end{tabular}

antisocial personality disorders have significantly higher scores than individuals in the control group. The Duncan post-hoc test showed that patients with borderline personality disorder had significantly lower scores in disconnection and rejection and otherdirectedness than patients with histrionic, narcissistic and antisocial personality disorders. The post-hoc comparisons by the Duncan test showed that patients with borderline and histrionic personality disorders had significantly lower scores in impaired autonomy and performance, impaired limits and over-vigilance and inhibition than patients with narcissistic and antisocial personality disorders. Altogether, the first hypothesis is positively affirmed in this study.

These findings from the first hypothesis align with the predictions of developmental psychopathology
(Bowlby, 1977; Erikson, 1963; Timmerman \& Emmelkamp, 2006); and cognitive therapy theories in the field of schemas (Beck, 1967; Wells, 2000; Wills \& Sanders, 2013). These findings showed that cluster B personality disorders were associated with several EMSs in ways consistent with the Schema Therapy model (Karp \& Dugas, 2003; Seavey \& Moore, 2012; Young, 1990; Young \& Klosko, 2005; Young, Klosko, \& Weishaar, 2003). These findings show how childhood trauma and adverse experiences may alter the pathway of personality development in a few pathological ways such as EMSs which work at subconscious and unconscious levels. Also, these findings are in line with predictions of the SFCT with regards to personality disorders (Karp \& Dugas, 2003; Seavey \& Moore, 2012; Young, 1990; Young \& Klosko, 2005; Young, Klosko, \& Weishaar, 


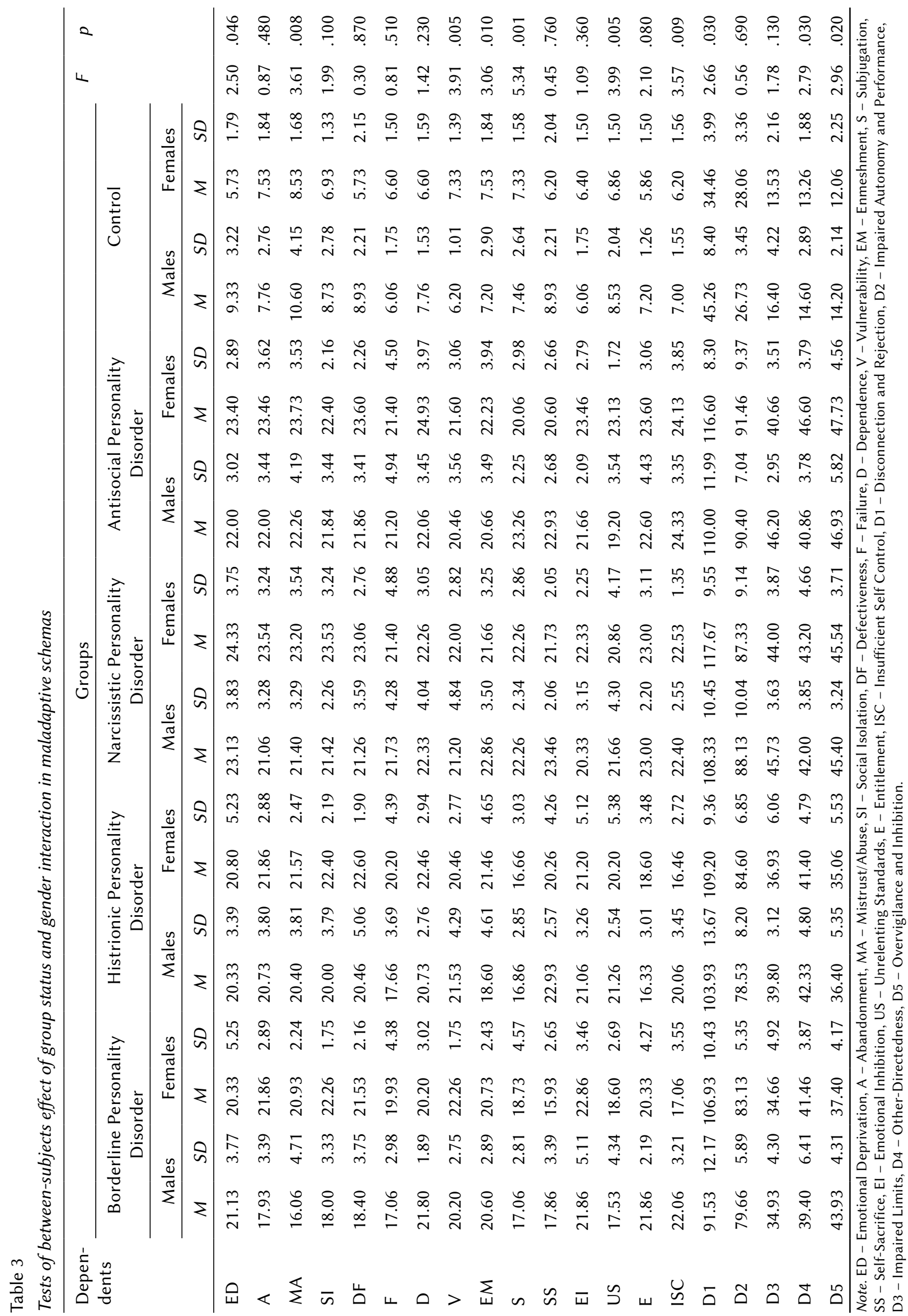


2003). While previous literature supported the role of EMSs in interpersonal problems and personality disorders, particularly borderline and antisocial personality disorders (Arntz, 2010; Arntz, Klokman, \& Sieswerda, 2005; Arntz \& van Genderen, 2009; Corral \& Calvete, 2014; Gullhaugen \& Nøttestad, 2012; Thimm, 2013; Özdel et al., 2015), the present findings show the importance of EMSs in emergence of the full range of cluster B personality disorders. Therefore, EMSs could be considered as important susceptibility factors for the development of some personality disorders, particularly the cluster B personality disorders.

This study suggestes that the roles of EMSs in the cluster B personality disorders can be explained by using self psychology, psychodynamic, dialectical behaviour therapy and cognitive perspectives (Cloninger, 1998; Davidson, 2000; Kernberg, 1975; Linehan, 1997; Masterson, 1997; McLean, 2007; Nolen-Hoeksema, 2001; Sue, Sue, \& Sue, 2006), since the EMSs may generate cluster B personality disorders through the presence of dysfunctional self with the persistence of abnormal cognitive, affective, and motivational patterns occurring through the individual's lifespan. This study suggests that individuals with cluster B personality disorders exist within their childhood needs, they are not capable of well-organized insight into their childhood motivations, they have many problems in emotional regulation, and they suffer from good ego strength in their current lives. Actually, the EMSs are a modern reformulation of previous psychodynamic theories and their contributions to the field of personality disorders. So, the present study shows the significance of personal insight toward unconscious childhood psychological traumas, and the implication of full self-knowledge for the treatment of individuals with cluster B personality disorders.

The results of the second hypothesis for gender differences in EMSs are positively confirmed in this sample. These findings showed that females had significantly higher scores in mistrust/abuse, emotional inhibition, and impaired autonomy and performance than males. In contrast, males had significantly higher scores in self-sacrifice than females. In addition, this study showed the role of personality disorder and gender interaction in emotional deprivation, mistrust/abuse, vulnerability, enmeshment, subjugation, unrelenting standards, and insufficient self-control schemas. Females with narcissistic and antisocial personality disorders had higher scores in emotional deprivation than males with similar personality disorders. Females with borderline, histrionic, narcissistic and antisocial personality disorders also had higher scores in mistrust/abuse than males with similar personality disorders. Females with borderline, narcissistic and antisocial personality disorders were indicated to have a higher score in vulnerability than males with similar personality disorders. Females with histrionic and antisocial personality disorders, once again, had a greater enmeshment score than males with similar personality disorders. Females with borderline personality disorder had higher scores in subjugation than males with the same personality disorders. However, men with antisocial personality disorder had higher scores in subjugation than women with the same disorder. Males with histrionic personality disorder had higher scores in unrelenting standards than females with a similar disorder. However, women with antisocial personality disorder had higher scores in unrelenting standards than men with the same disorder. Males with borderline, histrionic and narcissistic personality disorders had greater scores in insufficient self-control than females with similar personality disorders. Females with borderline personality disorders obtained higher scores in disconnection and rejection than males with similar personality disorders. Women with narcissistic and antisocial personality disorders had greater scores in the other-directedness domain than men with the same personality disorders. Males with borderline and histrionic personality disorders had greater scores in the over-vigilance and inhibition domain than females with same personality disorders. Also, women with antisocial personality disorder had higher levels of disconnection and rejection, other-directedness and overvigilance, and inhibition than men with the same personality disorder.

In general, there is limited literature about the influence of gender in early maladaptive schemas (Balsamo, Carlucci, Sergi, Klein Murdock, \& Saggino, 2015; El-Gilany, El-Bilsha, \& Ibrahim, 2013; Peixoto \& Nobre, 2015). Similarly, these findings are consistent with the predictions of theories in the fields of psychosocial development and cultural schemas (Timmerman \& Emmelkamp, 2006; Erikson, 1963; Malcolm \& Sharifian, 2002; Palmer, 1996; Piaget, 1970; Strauss \& Quinn, 1997; Wills \& Sanders, 2013). It seems that gender roles can help to explain gender differences in EMSs in this study. In line with the gender schema theory (Bem, 1993; Ryle, 2012), this study proposes that males and females have different schemas about their childhood experiences in the fields of cognitive, affective and social development. Therefore, this study advocates that gender schemas and gender-linked roles may result in different types of maladaptive schemas for males and females.

Overall, these findings about significant interaction of personality disorder and gender are congruent with the prior literature that supported the role of gender in cluster B personality disorders (Wood, 2007). These findings fit with the predictions of self psychology, psychodynamic, cognitive and gender schema theories (Bem, 1993; Cloninger, 1998; Davidson, 2000; Masterson, 1997; McLean, 2007; Kernberg, 1975; Nolen-Hoeksema, 2001; Sue, Sue, \& Sue, 2006). The present study suggests that gender schema might influence the incidence of personality disorders and 
early maladaptive schemas in both genders. Because gender typing is essential for a child's personality development it may to a large extent influence the child's perception of preferred social behavior and social judgments (Shaffer, 2009). This study assumes that gender typing, gender identity and gender schema can influence early maladaptive schemas in different ways among males and females with cluster B personality disorders. This explanation is consistent with the predictions of psychodynamic, cognitive development, gender schema, and social learning theories (Bem, 1993; Bussey, 2011; Pentony, 1980; Martin, Ruble, \& Szkrykablo, 2002; Shaffer, 2009). Since this culture has a sharp segregation in gender-linked roles for men and women, it might influence EMSs in patients with cluster B personality disorders.

Finally, the second hypothesis is negatively verified for age and educational differences in EMSs in this sample. This finding provides verification in an area in which convergence of evidence is not available, due to the lack of research on age and level of education variables in relation to early maladaptive schemas. This study recommends that further investigations with different age cohorts and a broader education status may help in the understanding of the effects of these variables in EMSs.

In conclusion, the present study adds to the existing literature with regards to personality disorders by indicating the presence of significantly higher levels of EMSs in patients with cluster B personality disorders, the exploration and significance of gender roles in EMSs, and the rejection of age and educational status effects on EMSs. Clinicians, as well as mental health and justice systems, may apply these findings for assessment, screening, intervention and prevention purposes. Also, results from this study can be used for instructional purposes with regards to cluster B personality disorders. However, this study has limitations, because it only used a self-rated, self-report measure and a small sample size in both clinical and non-clinical groups. Future studies are essential to understand how different childhood trauma and adverse experiences can influence the nature and severity of EMSs in various personality disorders. It could be interesting in future investigations to assess EMS by applying some kind of longitudinal/cohort designs, and it should be analyzed how EMSs may vary due to interventions. Further studies should investigate early maladaptive schemas and their neurocognitive and socio-cultural correlates in clinical and longitudinal samples, and use more sophisticated and objective measures.

\section{REFERENCES}

American Psychiatric Association (2013). Diagnostic and Statistical Manual of Mental Disorders DSM-V ( $5^{\text {th }}$ ed.). Arlington: American Psychiatric Association.
Arntz, A. (2010). New developments in schema therapy for borderline personality disorder. Sixth World Congress of Behavioral and Cognitive Therapies, 2-5 June, Boston.

Arntz, A., Klokman, J., \& Sieswerda, S. (2005). An experimental test of the schema mode model of borderline personality disorder. Journal of Behavior Therapy, 36, 226-339.

Arntz, A. \& van Genderen, H. (2009). Schema therapy for borderline personality disorder. Chichester: John Wiley \& Sons, Ltd.

Ball, J., Mitchell, P., Malhi, G., Skillecorn, A., \& Smith, M. (2003). Schema-focused cognitive therapy for bipolar disorder: Reducing vulnerability to relapse through attitudinal change. Australian and New Zealand Journal of Psychiatry, 37, 41-48. doi: 10.1046/j.1440-1614.2003.01098.x

Balsamo, M., Carlucci, L., Sergi, M. R., Klein Murdock, K., \& Saggino, A. (2015). The mediating role of early maladaptive schemas in the relation between co-rumination and depression in young adults. PLoS One, 10, e0140177. doi: 10.1371/journal.pone.0140177

Beck, A. T. (1967). Depression: Clinical, experimental, and theoretical aspects. New York: Harper and Row.

Beck, A. T., Freeman, A., Pretzer, J., Davis, D., Fleming, B., Ottaviani, R., Beck, J., Simon, K., Padesky, C. A., Meyer, J., \& Trexler, L. (1990). Cognitive therapy of personality disorders. New York: Guilford Press.

Beck, A. T., Rush, A. J., Shaw, B. F., \& Emery, G. (1979). Cognitive therapy for depression. New York: Guilford.

Bem, S. L. (1983). Gender schema theory and its implications for child development: Raising genderaschematic children in a gender-schematic society. Signs, 8, 598-616.

Bem, S. L. (1993). The lenses of gender: Transforming the debate on sexual equality. New Haven: Yale University Press.

Bloo, J., van Dyck, R., Spinhoven, P., van Tilburg, W., Dirksen, C., van Asselt,. T., Kremers, I., Nadort, M., \& Arntz, A. (2006). Outpatient psychotherapy for borderline personality disorder: Randomized trial of schema-focused therapy vs transference focused psychotherapy. Archive of General Psychiatry, 63, 649-658.

Bowlby, J. (1977). The making and breaking of affectional bonds: I. Aetiology and psychopathology in the light of attachment theory. British Journal of Psychiatry, 130, 201-210.

Bussey, K. (2011). Gender identity development. In S. J. Schwartz, K. Luyckx, \& V. L. Vignoles (eds.), Handbook of identity theory and research (pp. 603-628). New York: Springer.

Cloninger, C. R. (1998). The genetics and psychobiology of the seven-factor model of personality. In K. R. Silk (ed.), Biology of personality disorders. Washington: American Psychiatric Press. 
Corral, C., \& Calvete, E. (2014). Early maladaptive schemas and personality disorder traits in perpetrators of intimate partner violence. Spanish Journal of Psychology, 17, 1-10. doi: 10.1017/sjp.2014.1

Davidson, K. M. (2000) Cognitive therapy for personality disorders: A treatment manual. Oxford: Butterworth Heinemann.

El-Gilany, A. H., El-Bilsha, M. A., \& Ibrahim, A. (2013). Gender differences in maladaptive cognitive schema in orphans in Dakahlia, Egypt. The Scientific World Journal, 2013, 1-5. doi: 10.1155/2013/373120

Erikson, E. H. (1963). Childhood and society. New York: Norton.

Gullhaugen, A. S., \& Nøttestad, J. A. (2012). Under the surface: The dynamic interpersonal and affective world of psychopathic high-security and detention prisoners. International Journal of Offender Therapy and Comparative Criminology, 56, 917-936. doi: 10.1177/0306624X11415633

Karp, J., \& Dugas, M. J. (2003). Stuck behind a wall of fear: How cognitive-behavior therapy helped one woman with social phobia. Clinical Case Studies, 2, 171-187. doi: 10.1177/1534650103002003001

Kernberg, O. (1975). Borderline conditions and pathological narcissism. New York: Aronson Press.

Linehan, M. (1997). Dialectical behavior therapy (DBT) for borderline personality disorder. Journal of the California Alliance for the Mentally Ill, 8, 47-49.

Lobbestael, J., van Vreeswijk, M., Spinhoven, P., Schouten, E., \& Arntz, A. (2010). Reliability and validity of the Short Schema Mode Inventory (SMI). Behavioural and Cognitive Psychotherapy, 38, 437-458.

Malcolm, I. G., \& Sharifian, F. (2002). Aspects of aboriginal English oral discourse: An application of cultural schema theory. Discourse Studies, 4, 169181. doi: $10.1177 / 14614456020040020301$

Martin, C. L., Ruble, D. N., \& Szkrybalo, J. (2002). Cognitive theories of early gender development. Psychological Bulletin, 128, 903-933.

Masterson, J. F. (1997). The borderline disorder of the self. Journal of the California Alliance for the Mentally Ill, 8, 41-43.

McLean, J. (2007). Psychotherapy with a narcissistic patient using Kohut's self psychology model. Psychiatry (Edgmont), 4, 40-47.

Nolen-Hoeksema, S. (2001). Abnormal psychology ( $2^{\text {nd }}$ ed.). Boston: McGraw-Hill.

Norman, D. A., Rumelhart, D. E., \& the LNR Research Group (1975). Explorations in Cognition. San Francisco: Freeman.

Özdel, K., Turkey, A., Türkçapar, M. H., Guriz, S. O., Hamamci, Z., Duy, B., Taymur, I., \& Riskind, J. H. (2015). Early maladaptive schemas and core beliefs in antisocial personality disorder. International Journal of Cognitive Therapy, 8, 306-317.
Palmer, G. B. (1996). Toward a theory of cultural linguistics. Austin: University of Texas.

Palys, T. (2008). Purposive sampling. In L. M. Given (ed.), The Sage encyclopedia of qualitative research methods (Vol. 2, pp. 697-698). Thousand Oaks: Sage.

Peixoto, M. M. \& Nobre, P. (2015). Cognitive schemas activated in sexual context: A comparative study with homosexual and heterosexual men and women with and without sexual problems. Cognitive Therapy and Research, 39, 390-402. doi: 10.1007/s10608-014-9661-5

Pentony, C. G. (1980). Gender, sex typing, and gender identity. American Psychologist, 35, 941-942.

Petrocelli, J. V., Glaser, B. A., Calhoun, G. B., \& Campbell, L. F. (2001). Early maladaptive schemas of personality subtypes. Journal of Personality Disorders, $15,546-559$.

Piaget, J. (1970). Science of education and the psychology of the child. New York: Orion.

Rumelhart, D. E. (1980). Schemata: The building blocks of cognition. In R. J. Spiro, B. Bruce, \& W. F. Brewer (eds.), Theoretical issues in reading and comprehension (pp. 33-58). New Jersey: Erlbaum Hillsdale.

Ryle, R. (2012). Questioning gender: A sociological exploration. London: Sage.

Sadooghi, Z., Aguilar-Vafaie, M., Rasoulzadeh Tabatabaie, K., \& Esfehanian, N. (2008). Factor analysis of the Young Schema Questionnaire-Short Form in a nonclinical Iranian sample. Iranian Journal of Psychiatry and Clinical Psychology, 14, 214-219.

Schank, R. C. \& Abelson, R. (1977). Scripts, plans, goals, and understanding. Hillsdale: Erlbaum.

Schmidt, N. B., Joiner, T. E., Young, J. E., \& Telch, M. J. (1995). The schema questionnaire: Investigation of psychometric properties and the hierarchical structure of a measure of maladaptive schemas. Cognitive Therapy and Research, 19, 295-321.

Seavey, A., \& Moore, T. M. (2012). Schema-focused therapy for major depressive disorder and personality disorder: A case study. Clinical Case Studies, 11, 457-473. doi: 10.1177/1534650112460571

Shaffer, D. R. (2009). Social and personality development ( $6^{\text {th }}$ ed.). Belmont: Wadsworth.

Strauss, C., \& Quinn, N. (1997). A cognitive theory of cultural meaning. New York: Cambridge University Press.

Sue, D., Sue, D. W., \& Sue, S. (2006). Understanding abnormal behavior ( $8^{\text {th }}$ ed.). New York: Houghton Mifflin Company.

Sundag, J., Ascone, L., de Matos Marques, A, Moritz, S., \& Lincoln, T. M. (2016). Elucidating the role of Early Maladaptive Schemas for psychotic symptomatology. Psychiatry Research, 238, 53-59. doi: 10.1016/j.psychres.2016.02.008

Thimm, J. C. (2013). Early maladaptive schemas and interpersonal problems: A circumplex analysis of the YSQ-SF. International Journal of Psychology \& Psychological Therapy, 13, 113-124. 
Timmerman, I. G. H., \& Emmelkamp, P. M. G. (2006). The relationship between attachment styles and Cluster B personality disorders in prisoners and forensic inpatients. International Journal of Law and Psychiatry, 29, 48-56.

Tongco, M. D. C. (2007). Purposive sampling as a tool for informant selection. Ethnobotany Research \& Applications, 5, 147-158.

Trip, S. (2006). The Romanian version of Young Schema Questionnaire-Short Form 3. Journal of Cognitive and Behavior Psychotherapies, 6, 173-181.

Van Vreeswijk, M. F., van, Broersen, J., \& Nadort, M. (2012). The Wiley-Blackwell handbook of schema therapy: Theory, research and practice. Oxford: Wiley-Blackwell.

Welburn, K., Coristine, M., Dagg, P., Pontefract, A., \& Jordan, S. (2002). The Schema-Questionnaire short form: Factor analysis and relationship between schemas and symptoms. Cognitive Therapy and Research, 26, 519-530.

Wells, A. (2000). Emotional disorders and metacognition: Innovative cognitive therapy. Chichester: Wiley.

Wills, F., \& Sanders, D. (2013). Cognitive behaviour therapy: Foundations for practice $\left(3^{\text {rd }}\right.$ ed.) London: Sage.

Wood, J. T. (2007). Gendered lives: Communication, gender, and culture ( $7^{\text {th }}$ ed.). Toronto: Thomson Wadsworth.

Young, J. (1988). Schema-focused cognitive therapy for personality disorders. Paper presented at the Society for the Exploration of Psychotherapy Integration, April. Cambridge: MA.

Young, J. E. (1990). Cognitive therapy for personality disorders: A schema-focused approach. Sarasota: Professional Resource Press.

Young, J. E. (1998). Young Schema-Questionnaire Short Form. New York: Cognitive Therapy Centre.

Young, J., \& Klosko, J. (2005). Schema therapy. In J. M. Oldham, A. E. Skodol, \& D. S. Bender (eds.), The American psychiatric publishing textbook of personality disorders (pp. 289-306). Arlington: American Psychiatric Publishing.

Young, J. E., Klosko, J. S., \& Weishaar, M. (2003). Schema therapy: A practitioner's guide. New York: Guilford Publications. 